\title{
Motoneuron-Specific Expression of NR3B, a Novel NMDA-Type Glutamate Receptor Subunit That Works in a Dominant-Negative Manner
}

\author{
Mayumi Nishi, ${ }^{1}$ Heather Hinds, ${ }^{2}$ Hai-Ping Lu, ${ }^{1}$ Mitsuhiro Kawata, ${ }^{1}$ and Yasunori Hayashi ${ }^{2}$ \\ ${ }^{1}$ Department of Anatomy and Neurobiology, Kyoto Prefectural University of Medicine, Kawaramachi-Hirokoji, Kamigyo-ku, \\ Kyoto 602-8566, Japan, and 2RIKEN-MIT Neuroscience Research Center, Center for Learning and Memory, Department \\ of Brain and Cognitive Science, Massachusetts Institute of Technology, Cambridge, Massachusetts 02139
}

\begin{abstract}
We have identified a novel glutamate receptor subunit on the human and mouse genome. Cloning of the mouse cDNA revealed a protein consisting of 1003 amino acids encoded by at least nine exons. This protein showed the highest similarity $(51 \%)$ to the NR3A subunit of the NMDA receptor and therefore was termed NR3B. NR3B has a structure typical of glutamate receptor family members with a signal peptide and four membrane-associated regions. Amino acids forming a ligandbinding pocket are conserved. When coexpressed with NR1 and NR2A in heterologous cells, NR3B suppressed glutamateinduced current similarly to NR3A. Thus members of the NR3 class of NMDA receptors act as dominant-negative subunits in
\end{abstract}

Glutamate is the major excitatory neurotransmitter in the mammalian CNS. Its action is mediated by two distinct classes of glutamate receptors, ionotropic and metabotropic glutamate receptors (Seeburg, 1993; Nakanishi et al., 1996; Dingledine et al., 1999). The ionotropic glutamate receptor is a ligand-gated cation channel that passes cation with glutamate binding. It consists of several different subclasses including NMDA, AMPA, kainate, and $\delta$, which, in turn, are hetero-oligomers of several subunits (Seeburg, 1993; Hollmann and Heinemann, 1994; Dingledine et al., 1999). The NMDA receptor is composed of hetero-oligomers of NR1, NR2A-NR2D, and NR3A subunits (also called $\chi-1$ or NMDA receptor-like subunits). NR1 is a key subunit that confers essential functions of the NMDA receptor and is expressed ubiquitously in the CNS. In contrast, other subunits show more limited expression and confer a functional diversity. For example, during development of the visual cortex, NR2B is expressed predominantly in the early stages. After functional maturation of the cortex, predominant expression switches to NR2A (Quinlan et al., 1999). Concomitantly, the decay time course of the NMDA receptor-mediated synaptic current becomes faster (Carmignoto

Received Aug. 16, 2001; revised Sept. 18, 2001; accepted Sept. 19, 2001.

This study was supported in part by a grant-in-aid for scientific research from the Ministry of Education, Culture, Sports, Science, and Technology of Japan and by the Ellison Medical Foundation. We thank Drs. Kazutoshi Nakazawa, Satoshi Kaneko, Masahiko Watanabe, Ryosuke Takahashi, Hidenori Suzuki, and Takaaki Abe for valuable discussion and advice; Drs. Andrés Barría, Yoshitsugu Aoki, Nami Yamashita, Roberto Malinow, and Shigetada Nakanishi for the NR1 and NR2A cDNA expression vector constructs; and Dr. Jeffrey Diamond for the data acquisition program.

Correspondence should be addressed to Yasunori Hayashi, RIKEN-MIT Neuroscience Research Center, Center for Learning and Memory, Department of Brain and Cognitive Science, Massachusetts Institute of Technology E18-270, 77 Massachusetts Avenue, Cambridge, MA 02139. E-mail: yhayashi@mit.edu.

Copyright (C) 2001 Society for Neuroscience $0270-6474 / 01 / 210001-06 \$ 15.00 / 0$ the NMDA receptor complex. NR3B shows very restricted expression in somatic motoneurons of the brainstem and spinal cord. Its expression in other types of motoneurons, including autonomic motoneurons in Onuf's nucleus and oculomotor neurons, is significantly weaker. Our results indicate that NR3B is important as a regulatory subunit that controls NMDA receptor transmission in motoneurons. It may be involved in the pathogenesis of neurodegenerative diseases involving motoneurons as well.

Key words: NMDA-type glutamate receptor; genomic sequence; cDNA cloning; motoneurons; in situ hybridization; amyotrophic lateral sclerosis; Onuf's nucleus

and Vicini, 1992; Philpot et al., 2001). Dark rearing of animals, which prolongs the critical period of the visual cortex, delays this conversion (Quinlan et al., 1999).

In contrast to NR2 subunits, less is known about the NR3 class of subunits. To date, the NR3A subunit has been the only reported member of this class (Ciabarra et al., 1995; Sucher et al., 1995). NR3A is expressed ubiquitously during development and its expression level reaches a maximum at approximately the first postnatal week. Thereafter, the level gradually decreases, and in adult animals, NR3A is confined to limited nuclei in the thalamus, amygdala, and nucleus of the lateral olfactory tract (Ciabarra et al., 1995; Sucher et al., 1995). The NR3A subunit binds to NR1 and NR2 and acts in a dominant-negative manner against the NMDA receptor to reduce whole-cell current as well as single-channel conductance (Ciabarra et al., 1995; Sucher et al., 1995; Das et al., 1998; Perez-Otano et al., 2001). Consistent with this role for NR3A, mice lacking NR3A have a larger NMDA receptormediated current and an increased dendritic spine density in cerebrocortical neurons (Das et al., 1998), suggesting that the NR3A

This article is published in The Journal of Neuroscience, Rapid Communications Section, which publishes brief, peerreviewed papers online, not in print. Rapid Communications are posted online approximately one month earlier than they would appear if printed. They are listed in the Table of Contents of the next open issue of JNeurosci. Cite this article as: JNeurosci, 2001, 21:RC185 (1-6). The publication date is the date of posting online at www.jneurosci.org.

http://www.jneurosci.org/cgi/content/full/5880 
subunit is important for the development and plasticity of the CNS through a modulation of NMDA receptor function. Therefore, understanding the NR3 class of NMDA receptor subunits is important for understanding the physiology of the CNS.

In this report, we describe a novel NR3 subunit termed NR3B and characterize the structure, expression pattern, and electrophysiological properties of mouse NR3B.

\section{MATERIALS AND METHODS}

Identification of a novel glutamate receptor. We performed a basic local alignment search tool (BLAST) search on the published human genomic sequence using the amino acid sequence of the mouse $\delta 2$ subunit as a query sequence. This search detected a stretch of genomic sequence with significant homology to members of the glutamate receptor family on a contig from human chromosome 19p13.3 (GenBank accession number AC004528). We then used this sequence to search the unfinished high throughput genomic sequences database (including phases 0,1 , and 2 ) and identified the mouse homolog (accession numbers AC087114 and AC073805) on chromosome 10. A search of the expressed sequence tag (EST) database with these sequences identified the following ESTs: accession number AL040053 (human); accession numbers AW045848, BE864387, AW048083, and BE955769 (mouse); and accession numbers AW525909, BE108608, and BE112464 (rat). AW045848 and BE864387 are the same clone sequenced from opposite ends. We used this clone, which corresponds to the extracellular domain of the putative receptor, for screening of a mouse spinal cord cDNA library and in situ hybridization (Clontech, Palo Alto, CA).

Reverse transcriptase-PCR and in situ hybridization. We performed reverse transcriptase (RT)-PCR with primers spanning predicted exons 1 (CCTCTATAACCTTTCCCGAGG) and 2 (CTAGAGCAATGTCCTCCCAGG) of mouse NR3B. As a positive control for RT-PCR, we used a primer set for NR1 (5' primer, GATCCTCGAGCCATGGAGATCGCCTACAAGCGACAC; 3' primer, GATCGGATCCGCATGCTCAGCTCTCCCTATGACGGG). For in situ hybridizations on brain and spinal cord sections from male mice (C57BL/6, 6 weeks of age), we used either ${ }^{33} \mathrm{P}$ - or digoxigenin-labeled RNA probes (Simmons et al., 1989; Lu et al., 2001). Serotonin was immunohistochemically detected with anti-serotonin antibody (Incstar, Stillwater, MN).

Electrophysiology in human embryonic kidney 293. To express the receptors in human embryonic kidney (HEK)293 cells, we transfected the cells with $1 \mu \mathrm{g}$ of each plasmid unless otherwise stated (Shi et al., 1999). We tagged the NR1 and NR2A with green fluorescent protein (GFP) on the extracellular domain to facilitate the identification of transfected cells. Such constructs have been shown to preserve the properties of the glutamate receptor (Shi et al., 1999). NMDA receptormediated current was recorded in the presence of $10 \mu \mathrm{M}$ glycine. AMPA receptor current was recorded as described previously (Shi et al., 1999). Pipette solutions contained (in mM): cesium methanesulfonate $110, \mathrm{CsCl}$ 30, $\mathrm{NaCl} 4$, HEPES 10, EGTA 5, and $\mathrm{CaCl}_{2} 0.5$, adjusted to a $\mathrm{pH}$ of 7.3 with $\mathrm{CsOH}$. A $1 \mathrm{~mm}$ concentration of glutamate (for NMDA receptor) or kainate (for AMPA receptor) was pressure-applied (1.0 psi) through a puffer pipette positioned $\sim 10 \mu \mathrm{m}$ to the cells. We used a program based on Igor to acquire data on a Macintosh computer.

\section{RESULTS}

\section{Identification and cloning of a new mouse glutamate receptor}

A BLAST search of the published human and mouse genomic sequences identified a unique sequence with significant homology to the glutamate receptor family (Fig. $1 A$ ). We examined transcript levels as well as the tissue distribution of mRNA by RTPCR of mouse RNA using a primer set spanning the predicted exons 1 and 2 (Fig. 2A). It revealed a band of the expected size for spliced product in brainstem and spinal cord. We also detected a fainter band in the cerebellum. Using other primer sets covering exons 2 and 3, we detected a similar pattern of expression (data not shown). More rostral structures did not show any significant expression of this transcript, whereas RT-PCR for the NR1 subunit performed in parallel showed positive bands in all brain
A

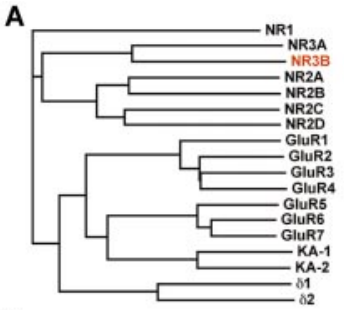

C

B

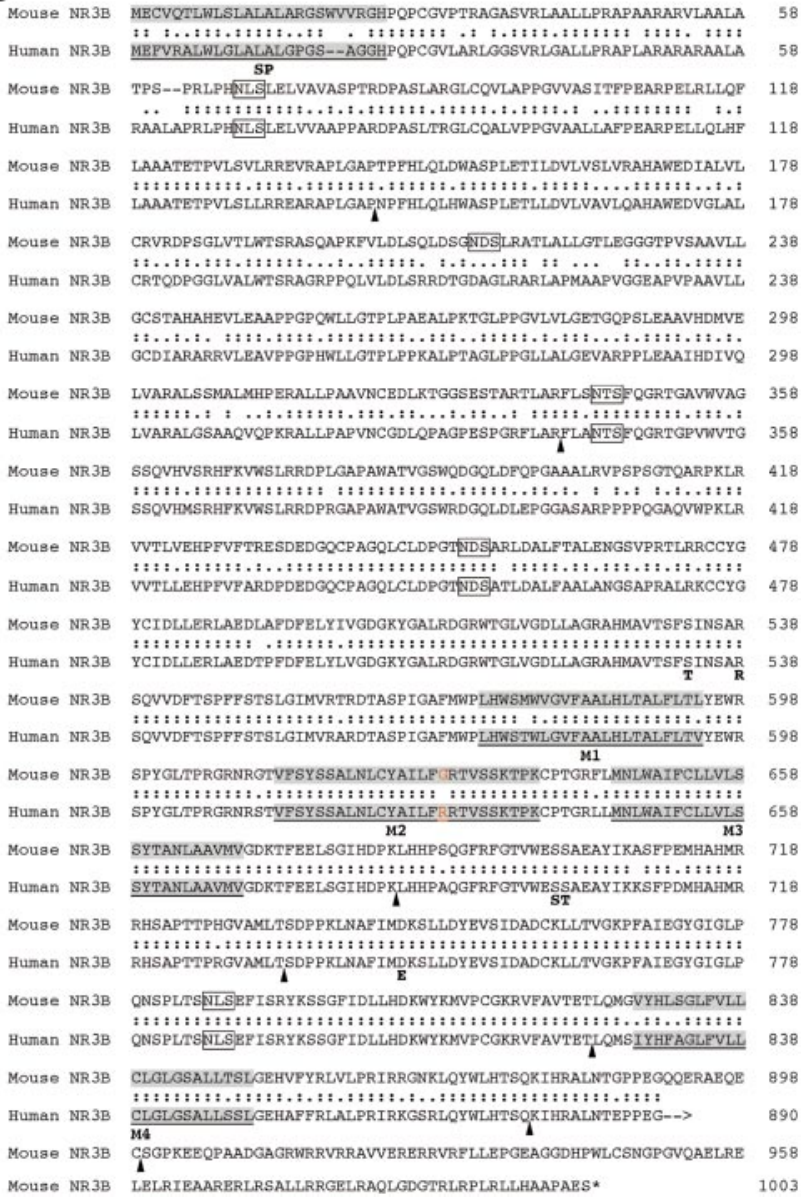

Figure 1. Structure of the glutamate receptor subtype NR3B. A, Phylogenic tree of the members of the glutamate receptor family based on the neighbor-joining method. The horizontal length of the branch indicates the distance between proteins. $B$, Mouse and human NR3B sequence. The human sequence is assembled from the genomic sequence and is not complete at the $\mathrm{C}$ terminus. Identical amino acids between two species are indicated by "." and homologous ones are indicated by ".". SP and M1-M4 indicate the predicted signal peptide and membrane-associated region, respectively. Putative glycosylation sites are boxed. Upward arrowheads indicate exon boundaries. Amino acids implicated in ligand binding of GluR2 from a crystallographic study are shown below the mouse sequence at the corresponding positions. $C$, A comparison of the M2 domain that forms a channel pore. The critical amino acid at the $\mathrm{Q} / \mathrm{R} / \mathrm{N}$ site, which controls ion permeability and rectification, is glycine followed by an arginine in both NR3B and NR3A (shown in red). In human NR3B, the $\mathrm{Q} / \mathrm{R} / \mathrm{N}$ site is an arginine $(B) . D$, Genomic structure of mouse NR3B. Open and shaded boxes are coding and noncoding regions, respectively. The $5^{\prime}$ noncoding region may extend further upstream.

regions. We did not detect the band when we omitted reverse transcriptase from the reaction (Fig. $2 A,-R T$ ), ruling out the possibility of amplification from contaminated genomic DNA. An additional BLAST search identified EST clones from humans, mice, and rats. When the mouse EST clone AW045848 was used 


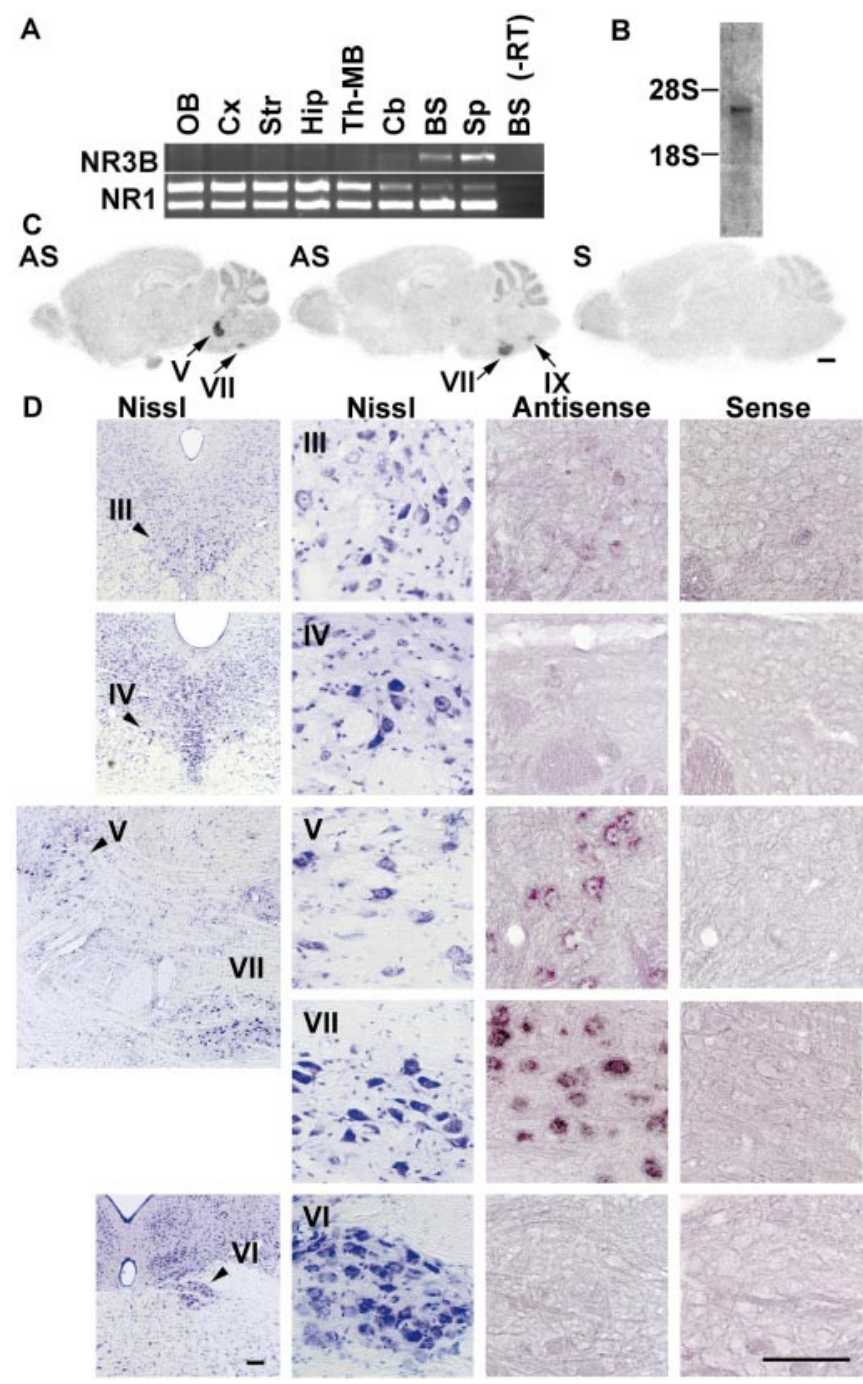

Figure 2. Tissue distribution of mouse NR3B. $A$, NR3B transcripts detected by RT-PCR with primers that span exons 1 and 2. The PCR product of the expected length was detected in the brainstem $(B S)$ and spinal cord $(S p)$ and to a much lesser extent in the cerebellum $(C b)$. When reverse transcriptase was omitted $(-R T)$, the product was not detected. As a positive control for RT-PCR, the NR1 was amplified in parallel, producing two bands that correspond to different slice variants. $O B$, Olfactory bulb; $C x$, cerebral cortex; Str, striatum; Hip, hippocampus; $T h-M B$, thalamus to midbrain region. $B$, Northern blot analysis of mouse spinal cord polyA ${ }^{+}$RNA detecting a single band at $\sim 3.5 \mathrm{~kb}$. C, In situ hybridization of sagittal sections of mouse brain with ${ }^{33} \mathrm{P}$-labeled antisense $(A S)$ and sense $(S)$ probes. The antisense probe detected a discrete signal in trigeminal motor $(V)$, facial $(V I I)$, and ambiguus $(I X)$ nuclei. The cerebellum also had a faint signal. $D$, Higher magnification of cranial nerve nuclei. A restricted expression of NR3B was detected in motoneurons that control somatic movement but not in those controlling ocular movement. Left, Low- and high-magnification images of Nissl-stained sections of oculomotor $(I I I)$, trochlear $(I V)$, trigeminal motor $(V)$, facial $(V I I)$, and abducens $(V I)$ nuclei are shown. Right, In situ hybridization using antisense and sense probes labeled with digoxigenin. A strong signal was observed in trigeminal motor and facial nuclei but not in those innervating extraocular muscles. Scale bars: $C, 1 \mathrm{~mm} ; D, 100 \mu \mathrm{m}$.

to probe polyA ${ }^{+}$RNA from mouse spinal cord, it hybridized to a band at $\sim 3.5 \mathrm{~kb}$ (Fig. $2 B$ ). We used this clone to screen a mouse spinal cord cDNA library. The screening of $\sim 10^{6}$ clones yielded three positive clones, one of which contained full-length cDNA (GenBank accession number AF396649).

\section{Structure of the NR3B gene, cDNA, and protein product}

Sequence analysis of the clone revealed a cDNA of $3283 \mathrm{bp}$ encoding a protein of 1003 amino acids (Fig. $1 B$ ). The cDNA is encoded by at least nine exons in the mouse genome spanning $\sim 6.5 \mathrm{~kb}$ (Fig. 1D). A TATA box is found in the genomic sequence at -339 from the start codon ATG, whereas the cDNA starts at -185 , suggesting that a $5^{\prime}$ untranslated sequence exists beyond our cDNA. All nucleotides in the genomic sequence and the cDNA are identical, indicating that RNA editing does not occur in this gene. The predicted protein has a significant similarity to NR3A (51\%); therefore, we named it NR3B (Fig. 1A). A glutamate receptor member named $\chi$-2 has been reported in abstract form, but because of a lack of detailed information, the identity of NR3B with $\chi$-2 is obscure (Sevarino et al., 1996). The human sequence was assembled from the genomic sequence deposited in GenBank (Fig. 1B) (third-party annotation section of DNA Data Bank of Japan/European Molecular Biology Laboratory/GenBank accession number Bk 000070). The $\mathrm{C}$ terminus of the human clone loses homology after Gly890, which is followed by a possible splice donor site (GGG $\underline{\mathrm{T}}$ ), indicating that there may be one or more additional exons in the human sequence. All of the other exon-intron boundaries are preserved between the two species and conform to a consensus splice donor-acceptor site (GT-AG). The homology between the human and mouse sequence is $81.3 \%$.

NR3B has a transmembrane topology that is typical of glutamate receptors with an $\mathrm{N}$-terminal signal peptide and four membrane-associated regions. Five (in mice) or four (in humans) consensus sequences for $\mathrm{N}$-glycosylation sites are found on the $\mathrm{N}$-terminal domain, and one (for both species) is found at the loop between the third and fourth membrane-associated regions. The intracellular $\mathrm{C}$ terminus of mouse NR3B has three threonines and five serines, which may serve as regulatory phosphorylation sites. The $\mathrm{C}$ terminus ends with Ala-Glu-Ser, which does not conform to the consensus (PSD-05, Dlg, Z0-1) domain protein-binding site sequence typical of other glutamate receptor family members (Songyang et al., 1997; Sheng and Sala, 2001).

The amino acid residues forming the glutamate-binding pocket have been elucidated by structural studies of the crystallized ligand-binding domain of glutamate receptor 2 (GluR2) (Armstrong and Gouaux, 2000). Importantly, the 2-carboxyl group of glutamate binds to the guanidium group of Arg485 and the amino H group of Thr480; the 2-amino group interacts with the carboxyl group of Glu705 in GluR2. These residues can be mapped precisely on the sequence of NR3B with Thr480 of GluR2 corresponding to Ser533 of NR3B, Arg485 to Arg538, and Glu705 to Asp745. Other amino acids forming the putative ligand-binding pocket are also well conserved (Fig. 1B), indicating that NR3B itself is likely to bind to glutamate.

\section{Expression of NR3B is limited to motoneurons}

The RT-PCR revealed that NR3B is expressed selectively in a limited number of brain regions. In situ hybridization of a sagittal section of a mouse brain consistently detected signal in limited regions in the brainstem (Fig. 2C). A counterstaining of the sections (data not shown) showed that these are the trigeminal motor (V), facial (VII), and ambiguus (IX) nuclei. A higher magnification of these structures revealed hybridization signals in motoneurons with large cell bodies (Fig. 2D). In contrast, the signal was significantly weaker in motoneurons in the nuclei 


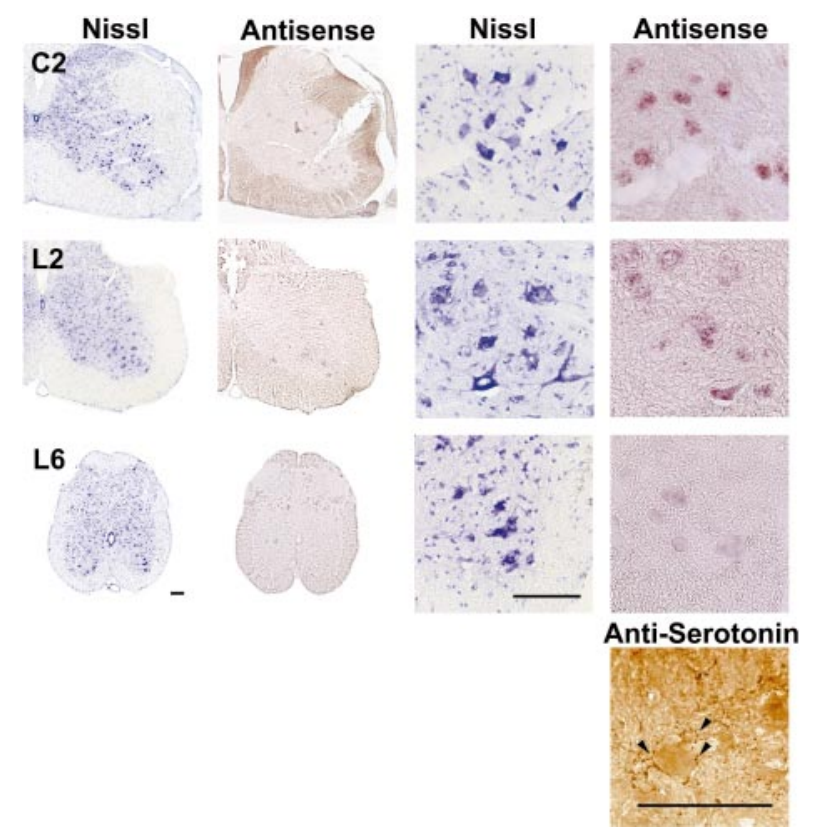

Figure 3. Expression of NR3B in spinal cord. Left, Low-magnification images of sections stained with Nissl and adjacent sections hybridized with antisense probe. Right, Higher magnification of the same sections. Somatic motoneurons are strongly labeled at the $C 2$ and $L 2$ levels. In contrast, the expression of NR3B was significantly weaker in the motoneurons at the $L 6$ level. There was a plexus of serotonin immunoreactive fibers (arrowheads) surrounding these cells, which is one of the characteristics of motoneurons in Onuf's nucleus. Scale bars, $100 \mu \mathrm{m}$.

controlling the external ocular muscles (Fig. 2D, III, oculomotor; $I V$, trochlear; and $V I$, abducens).

In the spinal cord, the signal was also detected in the motoneurons in the anterior horn (Fig. 3). However, at the L6 level, the signal intensity of NR3B in motoneurons was significantly weaker than at higher levels, although the presence of motoneurons at this level was confirmed by Nissl staining. These motoneurons were classified as those in Onuf's nucleus, which controls external anal and urethral sphincters, based on plexus formation of serotonin immunoreactive fibers on the cell body (Fig. 3, bottom) (Micevych et al., 1986) and a comparison with the cytoarchitecture of the mouse spinal cord (Sidman et al., 1971) as well as with previous studies on a rat counterpart (Schroder, 1980; McKenna and Nadelhaft, 1986). However, because of a lack of systematic analyses of Onuf's nucleus in the mouse, this assignment is tentative and awaits more extensive study (for example, a retrograde labeling) to be conclusive.

\section{NR3B acts as a dominant-negative subunit}

Finally, we tested the electrophysiological properties of NR3B by expressing NR3B in HEK293 cells. A conventional NMDA receptor channel is formed by a heteromeric combination of NR1, which is a key subunit for functionality, and at least one NR2 subunit, which is modulatory (Dingledine et al., 1999). NR3B cannot substitute for either of these subunits, because expression of NR3B alone $(n=6)$ or coexpression with NR1 $(n=6)$ or NR2A $(n=5)$ did not result in electrophysiologically functional channels (data not shown), whereas coexpression of NR1 and NR2A gave a robust current (Fig. 4). However, coexpression of all three subunits markedly depressed the whole-cell current compared with the combination of NR1 and NR2A (Fig. 4A,C). Increasing the amount of NR3B versus the other subunits had a stronger sup-
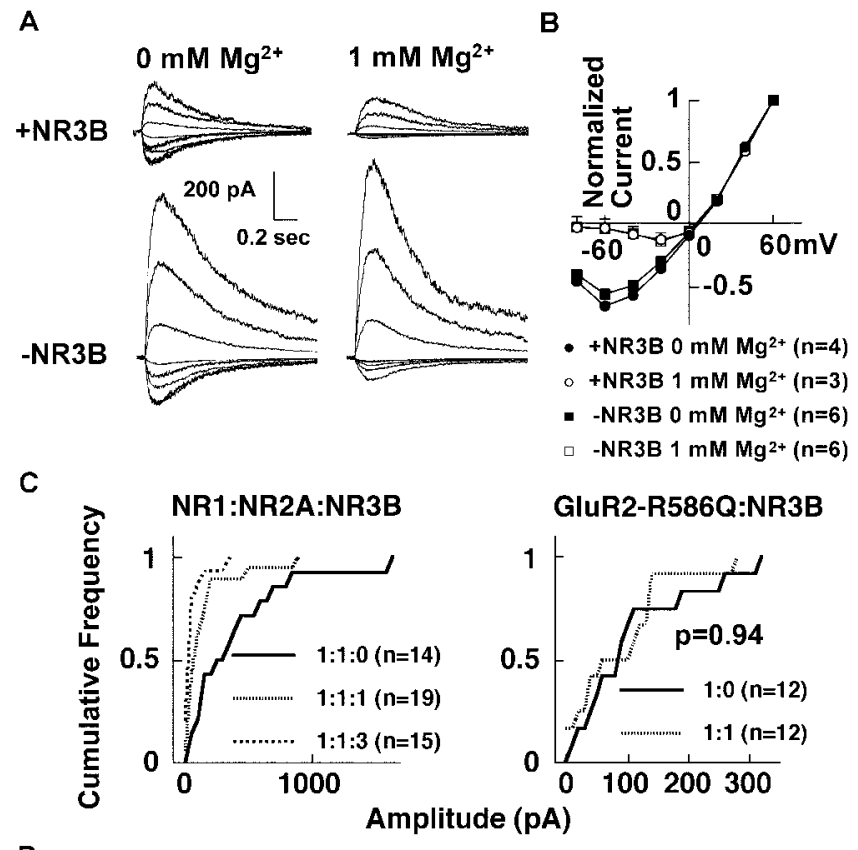

D

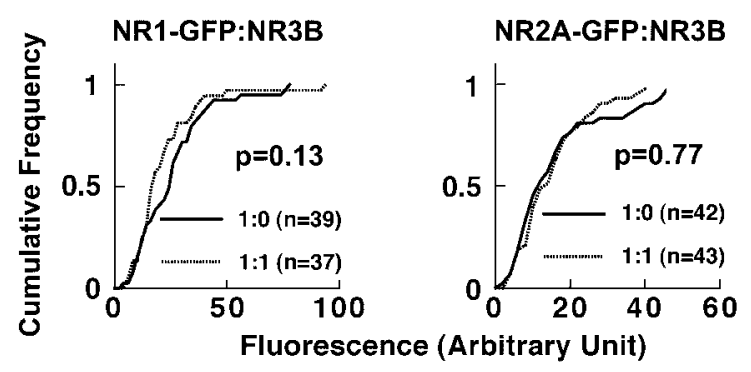

Figure 4. Glutamate-induced whole-cell current recorded from HEK293 cells expressing NR3B. NR3B was coexpressed with the NR1 and NR2A subunits. $A$, Sample traces of glutamate-induced current recorded at -80 to $+60 \mathrm{mV}\left(20 \mathrm{mV}\right.$ step) in the presence or absence of $1 \mathrm{mM} \mathrm{Mg}^{2+} . B$, The remaining current in NR3B-expressing cells exhibits a $\mathrm{Mg}^{2+}$ block indistinguishable from cells not expressing NR3B. The slight block at -60 and $-80 \mathrm{mV}$ may be attributable to residual $\mathrm{Mg}^{2+}$. C, NR3B acts as a dominant-negative subunit and suppresses glutamate-induced wholecell current in cells coexpressing NR1 and NR2A. The distribution of averaged responses obtained at $+60 \mathrm{mV}$ in $\mathrm{Mg}^{2+}$-free solution is shown in a cumulative plot. Increasing the amount of NR3B plasmid $(0,1$, and $3 \mu \mathrm{g}$ ) versus other subunits (each $1 \mu \mathrm{g}$ ) caused a concomitant decrease in current amplitude. Statistical significances were as follows: 1:1:0 vs 1:1:1, $p<0.05$; $1: 1: 0$ vs 1:1:3, $p<0.01$; and 1:1:1 vs $1: 1: 3, p<0.01$. AMPA receptor-mediated current was unchanged by coexpression with NR3B. GluR2-(R586Q)-GFP was used because we know empirically that this construct gives a reliable response. $D$, Coexpression with NR3B did not change the expression levels of NR1 or NR2A. NR1 and NR2A tagged with GFP were individually expressed with NR3B and their expression levels were measured by the fluorescence intensity. The statistical significance in this figure was assessed by a Kolmogorov-Smirnov test.

pressive effect (Fig. 4C). This is not attributable to a nonspecific reduction of the protein expression level, because a direct quantification of expression levels of NR1 and NR2A tagged with GFP using fluorescence as a measure did not show any significant difference in the presence or absence of NR3B (Fig. 4D). The effect of NR3B is specific to the NMDA receptor, because the AMPA receptor-mediated current was not changed by the presence of NR3B (Fig. 4C). The sensitivity of the remaining current to $\mathrm{Mg}^{2+}$ block was not affected by the presence of NR3B subunit (Fig. 4B). 


\section{DISCUSSION}

We have identified a novel glutamate subunit, NR3B. The most intriguing feature of this receptor is its expression pattern. It is almost exclusively expressed in somatic motoneurons in cranial nerve nuclei (including trigeminal motor and facial nuclei) and in the spinal anterior horn, which control somatic movement. In addition to these somatic motoneurons, there are other classes of motoneurons. The extraocular muscles are controlled by motoneurons originating from the oculomotor, trochlear, and abducens nuclei. Also, external urethral and anal sphincter muscles are controlled by a distinct group of motoneurons present in Onuf's nucleus in lower spinal cord (Mannen et al., 1982; Anneser et al., 1999). These different classes of motoneurons are affected differently under pathological conditions. As a typical example, in amyotrophic lateral sclerosis (ALS), a selective loss of somatic motoneurons is observed but no loss of those autonomic motoneurons and oculomotor neurons is apparent (Mannen et al., 1982; Anneser et al., 1999; Nimchinsky et al., 2000). Given the importance of glutamate neurotoxicity in various neurodegenerative diseases (Choi, 1992), we tested the expression of NR3B in those motoneurons. Strikingly, less expression was clearly observed in these structures compared with the somatic motoneurons (Figs. 2 and 3). This selective expression of NR3B in somatic motoneurons versus other types of neurons may explain a selective loss of somatic motoneurons in ALS. The low but not absent level of expression is consistent with the fact that incontinence and opthalmoplegia still appear at the terminal stage after prolonged respiratory support (Palmowski et al., 1995).

In the glutamate receptor family, the second membraneassociated domain forms a channel pore. The critical site for determining ion channel permeability and the selectivity of glutamate receptors is called the Q/R/N site (Seeburg, 1993; Hollmann and Heinemann, 1994; Dingledine et al., 1999). Non-NMDA receptors have either a glutamine or an arginine, and the presence of arginine confers a linear IV relationship and the monovalent cation selectivity of this class of channel. In NR1 and NR2 subtypes of NMDA receptor, this site is asparagine and it is critical for the $\mathrm{Mg}^{2+}$ block at negative potential and the $\mathrm{Ca}^{2+}$ permeability of this channel. The corresponding residue of $\mathrm{NR} 3 \mathrm{~B}$ is glycine followed by an arginine, which may also be important for determining the channel properties. This feature is shared with NR3A (Fig. $1 C$ ). Previous reports indicate that coexpression of NR3A with NR1 and NR2 also decreases whole-cell current (Ciabarra et al., 1995; Sucher et al., 1995) as well as single-channel conductance (Das et al., 1998; Standley et al., 2000). A similar mechanism may explain an observed decrease in the whole-cell current in NR3B-expressing cells. In fact, in an outside-out patch obtained from motoneurons, one study detected a decreased conductance channel (Paleček et al., 1999).

Alternatively, this decrease in whole-cell current could be explained by a decrease in the surface delivery of functional receptors. For example, NR1A has an endoplasmic reticulum retention signal at the intracellular $\mathrm{C}$ terminus (Standley et al., 2000; Scott et al., 2001). Also, the AMPA receptor subtype GluR1 has a delivery signal to the synaptic surface, which retains GluR1 in the absence of $\mathrm{Ca}^{2+} /$ calmodulin-dependent protein kinase II activity (Hayashi et al., 2000; Shi et al., 2001). A similar mechanism may be involved in the regulation of the NMDA receptor by the NR3B subunit.

Because of this dominant-negative role of the NR3B subunit, downregulation or dysfunction of NR3B would lead to enhanced NMDA receptor activity, which may increase the vulnerability of neurons to excitotoxicity. Considering the relatively specific expression of NR3B in somatic motoneurons, reduction of NR3B (for example, by a genetic mutation) may specifically affect somatic motoneurons. Alternatively, an autoimmune antibody against NR3B could have a similar impact on somatic motoneurons, as has been shown for other classes of receptors and channels (Appel et al., 1993; Rogers et al., 1994; Smitt et al., 2000). Such mechanisms may explain the selective loss of somatic motoneurons in ALS. Further characterization of NR3B is indispensable for a precise understanding of the physiology and pathophysiology of motoneurons.

\section{REFERENCES}

Anneser JM, Borasio GD, Berthele A, Zieglgansberger W, Tölle TR (1999) Differential expression of group I metabotropic glutamate receptors in rat spinal cord somatic and autonomic motoneurons: possible implications for the pathogenesis of amyotrophic lateral sclerosis. Neurobiol Dis 6:140-147.

Appel SH, Smith RG, Engelhardt JI, Stefani E (1993) Evidence for autoimmunity in amyotrophic lateral sclerosis. J Neurol Sci 118:169-174.

Armstrong N, Gouaux E (2000) Mechanisms for activation and antagonism of an AMPA-sensitive glutamate receptor: crystal structures of the GluR2 ligand binding core. Neuron 28:165-181.

Carmignoto G, Vicini S (1992) Activity-dependent decrease in NMDA receptor responses during development of the visual cortex. Science 258:1007-1011.

Choi DW (1992) Excitotoxic cell death. J Neurobiol 23:1261-1276.

Ciabarra AM, Sullivan JM, Gahn LG, Pecht G, Heinemann S, Sevarino KA (1995) Cloning and characterization of $\chi$-1: a developmentally regulated member of a novel class of the ionotropic glutamate receptor family. J Neurosci 15:6498-6508.

Das S, Sasaki YF, Rothe T, Premkumar LS, Takasu M, Crandall JE, Dikkes P, Conner DA, Rayudu PV, Cheung W, Chen HS, Lipton SA, Nakanishi N (1998) Increased NMDA current and spine density in mice lacking the NMDA receptor subunit NR3A. Nature 393:377-381.

Dingledine R, Borges K, Bowie D, Traynelis SF (1999) The glutamate receptor ion channels. Pharmacol Rev 51:7-61.

Hayashi Y, Shi SH, Esteban JA, Piccini A, Poncer JC, Malinow R (2000) Driving AMPA receptors into synapses by LTP and CaM KII: requirement for GluR1 and PDZ domain interaction. Science 287:2262-2267.

Hollmann M, Heinemann S (1994) Cloned glutamate receptors. Annu Rev Neurosci 17:31-108.

Lu H, Ozawa H, Nishi M, Ito T, Kawata M (2001) Serotonergic neurones in the dorsal raphe nucleus that project into the medial preoptic area contain oestrogen receptor $\beta$. J Neuroendocrinol 13:839-845.

Mannen T, Iwata M, Toyokura Y, Nagashima K (1982) The Onuf's nucleus and the external anal sphincter muscles in amyotrophic lateral sclerosis and Shy-Drager syndrome. Acta Neuropathol 58:255-260.

McKenna KE, Nadelhaft I (1986) The organization of the pudendal nerve in the male and female rat. J Comp Neurol 248:532-549.

Micevych PE, Coquelin A, Arnold AP (1986) Immunohistochemical distribution of substance $\mathrm{P}$, serotonin, and methionine enkephalin in sexually dimorphic nuclei of the rat lumbar spinal cord. J Comp Neurol 248:235-244.

Nakanishi S, Nakajima Y, Nomura A, Masu M, Iwakabe H, Hayashi Y, Yokoi M (1996) Functions and roles of glutamate receptors in synaptic transmission and plasticity. Cold Spring Harb Symp Quant Biol 61:67-75.

Nimchinsky EA, Young WG, Yeung G, Shah RA, Gordon JW, Bloom FE, Morrison JH, Hof PR (2000) Differential vulnerability of oculomotor, facial, and hypoglossal nuclei in G86R superoxide dismutase transgenic mice. J Comp Neurol 416:112-125.

Paleček JI, Abdrachmanova G, Vlachová V, Vyklickẏ Jr L (1999) Properties of NMDA receptors in rat spinal cord motoneurons. Eur J Neurosci 11:827-836.

Palmowski A, Jost WH, Prudlo J, Osterhage J, Käsmann B, Schimrigk K, Ruprecht KW (1995) Eye movement in amyotrophic lateral sclerosis: a longitudinal study. Ger J Ophthalmol 4:355-362.

Perez-Otano I, Schulteis CT, Contractor A, Lipton SA, Trimmer JS, Sucher NJ, Heinemann SF'(2001) Assembly with the NR1 subunit is required for surface expression of NR3A-containing NMDA receptors. J Neurosci 21:1228-1237.

Philpot BD, Sekhar AK, Shouval HZ, Bear MF (2001) Visual experience and deprivation bidirectionally modify the composition and function of NMDA receptors in visual cortex. Neuron 29:157-169.

Quinlan EM, Philpot BD, Huganir RL, Bear MF (1999) Rapid, 
experience-dependent expression of synaptic NMDA receptors in visual cortex in vivo. Nat Neurosci 2:352-357.

Rogers SW, Andrews PI, Gahring LC, Whisenand T, Cauley K, Crain B, Hughes TE, Heinemann SF, McNamara JO (1994) Autoantibodies to glutamate receptor GluR3 in Rasmussen's encephalitis. Science 265:648-651.

Schroder HD (1980) Organization of the motoneurons innervating the pelvic muscles of the male rat. J Comp Neurol 192:567-587.

Scott DB, Blanpied TA, Swanson GT, Zhang C, Ehlers MD (2001) An NMDA receptor ER retention signal regulated by phosphorylation and alternative splicing. J Neurosci 21:3063-3072.

Seeburg PH (1993) The TiPS/Trends Neurosci lecture: the molecular biology of mammalian glutamate receptor channels. Trends Pharmacol Sci 14:297-303.

Sevarino KA, Ciabarra AM, Forcina MS (1996) $\chi$-1 and $\chi$-2, members of a novel class of the glutamate receptor superfamily. Soc Neurosci Abstr 22:592.

Sheng M, Sala C (2001) PDZ domains and the organization of supramolecular complexes. Annu Rev Neurosci 24:1-29.

Shi S-H, Hayashi Y, Petralia R, Zaman S, Wenthold R, Svoboda K, Malinow R (1999) Rapid spine delivery and redistribution of AMPA receptors after synaptic NMDA receptor activation. Science 284:18111816.

Shi S-H, Hayashi Y, Esteban JA, Malinow R (2001) Subunit-specific rules governing AMPA receptor trafficking to synapses in hippocampal pyramidal neurons. Cell 105:331-343.

Sidman RL, Angevine Jr JB, Pierce ET (1971) Atlas of the mouse brain and spinal cord. Cambridge, MA: Harvard UP, A Commonwealth Fund Book.

Simmons DM, Arriza JL, Swanson LW (1989) A complete protocol for in situ hybridization of messenger RNAs in brain and other tissues with radiolabeled single-stranded RNA probes. J Histotechnol 12:169-181.

Smitt PS, Kinoshita A, De Leeuw B, Moll W, Coesmans M, Jaarsma D, Henzen-Logmans S, Vecht C, De Zeeuw C, Sekiyama N, Nakanishi S, Shigemoto R (2000) Paraneoplastic cerebellar ataxia due to autoantibodies against a glutamate receptor. N Engl J Med 342:21-27.

Songyang Z, Fanning AS, Fu C, Xu J, Marfatia SM, Chishti AH, Crompton A, Chan AC, Anderson JM, Cantley LC (1997) Recognition of unique carboxyl-terminal motifs by distinct PDZ domains. Science 275:73-77.

Standley S, Roche KW, McCallum J, Sans N, Wenthold RJ (2000) PDZ domain suppression of an ER retention signal in NMDA receptor NR1 splice variants. Neuron 28:887-898.

Sucher NJ, Akbarian S, Chi CL, Leclerc CL, Awobuluyi M, Deitcher DL, Wu MK, Yuan JP, Jones EG, Lipton SA (1995) Developmental and regional expression pattern of a novel NMDA receptor-like subunit (NMDAR-L) in the rodent brain. J Neurosci 15:6509-6520. 